\title{
Electronic Markets on the next convergence
}

\author{
Rainer Alt ${ }^{1}$ \\ Published online: 29 March 2021 \\ (C) The Author(s) 2021
}

This issue of Electronic Markets includes a special issue on the Internet of Things (IoT) and a cluster of general research articles on social commerce. While being related to different technological enablers, IoT and social media are closely connected to a confluence of various previously separate technologies. In the case of IoT, physical devices with sensors or actuators are connected via wireless networks, standards (e.g. by ISO JTC 1) and digital platforms. Social media in turn are based on an amalgamation of Internet network technologies (e.g. HTTP, HTML), Web 2.0 applications (e.g. blogs, RSS) and cloud platforms. Both technologies have also shown to complement each other in numerous application scenarios. Among the examples are the inclusion of users to save energy in smart buildings and environments (Crowley et al. 2014) or location-based social media campaigns in combination with various kinds of wearables (Maiorescu et al. 2020). Such convergence has been a property of technological evolution for decades and led to continuous improvements in quantitative (e.g. speed, energy efficiency) and/or qualitative (e.g. functionality, usability) terms. This power of convergence has triggered upheaval in many industries and also gave birth to new businesses. The following first glances at several past developments before it discusses the foreseeable "next convergence".

\section{Convergence as multifaceted term}

Starting research on convergence quickly reveals that the term is used in many application contexts. In her "introduction to a confusing term", Balbi (2017, p. 31) elaborates on the origins of convergence, which are rooted in the eighteenth century and evolved from the discipline of ray physics across other disciplines such as mathematics and biology as well as to the

Rainer Alt

rainer.alt@uni-leipzig.de

1 Information Systems Institute, Leipzig University, Grimmaische Str. 12, 04109 Leipzig, Germany social sciences and humanities during the twentieth century. In the technological context, convergence already existed before the dawn of digital technologies, for example with synergies between telegraph and press companies (Balbi 2017, p. 34). However, it was only with the rise of digital technologies that convergence reached its profound impetus. The role of digital technology as "common currency for convergence" (Rolland 2003, p. 16) was most visible with technological digitalization (or digitization), which allowed for transferring analog into binary values and for easily storing as well as sharing these values in databases and networks. This technological dimension of digitalization (Alt 2018) is also reflected in the first dimension of convergence in Table 1. It includes the convergence of digital content as well as the convergence of networks with examples such as voice over IP (VoIP) or triple and quadruple play (e.g. Hens and Caballero 2008) as well the convergence of devices. The latter is visible in complex devices like smartphones, which replace several previously separate devices (e.g. navigation device, camera, torch, clock, wallet, media player). As with many multifunctional devices, this integration comes with a tradeoff since the broader overall functional spectrum is often inferior to the more sophisticated specialized separate devices.

The convergence of devices and their functionality is closely related to the dimension of products and processe (see Table 1). Obviously, the devices are hardware products in themselves and their functionality is often determined by software products (e.g. operating system, digital services). Following Greenstein and Khanna (1997, p. 203f) "two products converge in complements when the products work better together than separately or when they work better together now than they worked together formerly". Despite being more complex in itself, the ability to access many services via a single device reduces the complexity for the user and thereby creates value. The same occurs with interaction channels and processes, where convergence leads to a coordination among channels and the combination of process models of various organizations into a crossover model. From an organizational perspective, convergence was also related to the business-IT alignment discussion, which is necessary as digitalization 
Table 1 Convergence in various dimensions

\begin{tabular}{|c|c|}
\hline Dimension & Converging aspects \\
\hline \multirow[t]{4}{*}{ 1. Technologies and infrastructures } & $\begin{array}{l}\text { - Content / digital / media convergence: convergence of formats } \\
\text { based on the digitalization of content (Stobbe and Just 2006; } \\
\text { Vukanovic 2018) }\end{array}$ \\
\hline & $\begin{array}{l}\text { - Device / terminal convergence: devices that combine many } \\
\text { functions and support many content formats, e.g. smartphone, } \\
\text { Smart TV (Rolland 2003; Park 2019) }\end{array}$ \\
\hline & $\begin{array}{l}\text { - Network / service convergence: integration of communication } \\
\text { services (e.g. voice, data, TV) in the same transmission } \\
\text { network, e.g. VOIP, IPTV, triple and quadruple play (Rolland } \\
\text { 2003; Castells 2007; Meikle and Young 2011) }\end{array}$ \\
\hline & $\begin{array}{l}\text { - Technological convergence (in general): two or more } \\
\text { independent technologies integrate and form a new outcome } \\
\text { (Park 2019) }\end{array}$ \\
\hline \multirow[t]{4}{*}{ 2. Products and processes } & $\begin{array}{l}\text { - Channel convergence: move from separate interaction channels } \\
\text { to omni-channel management (Hübner et al. 2016) }\end{array}$ \\
\hline & $\begin{array}{l}\text { - Organizational convergence: merging of business and } \\
\text { technological areas and skills (Hoque et al. 2011) }\end{array}$ \\
\hline & $\begin{array}{l}\text { - Product convergence: merging of previously separate products in } \\
\text { one product (Gustavsson and Schwarz 2013) }\end{array}$ \\
\hline & $\begin{array}{l}\text { - Process convergence: merging of services from various providers } \\
\text { towards crossover services ( } \mathrm{Li} \text { et al. } 2015 \text {, Shan et al. 2020) }\end{array}$ \\
\hline \multirow[t]{2}{*}{ 3. Markets and industries } & $\begin{array}{l}\text { - Industry convergence: coming together of two or more hitherto } \\
\text { separate industries (Greenstein and Khanna 1997; Wirtz 1999; } \\
\text { Park 2019) }\end{array}$ \\
\hline & $\begin{array}{l}\text { - Market convergence: infiltration of previously separate } \\
\text { economic sectors resulting in mergers and acquisitions (Wirtz } \\
\text { 1999; Rolland 2003). }\end{array}$ \\
\hline \multirow[t]{3}{*}{ 4. Networks and ecosystems } & $\begin{array}{l}\text { - Architectural convergence: convergence of multiple enabling } \\
\text { platforms (Srinivasan and Venkatraman 2020) }\end{array}$ \\
\hline & $\begin{array}{l}\text { - Business model convergence: convergence of value creation } \\
\text { logic (e.g. from pipeline to platform or vice versa) (Mody et al. } \\
\text { 2020; Rolland 2003) }\end{array}$ \\
\hline & $\begin{array}{l}\text { - Platform / ecosystem convergence: convergence of various } \\
\text { platforms and / or ecosystems (Srinivasan and Venkatraman } \\
\text { 2020; Basole 2009) }\end{array}$ \\
\hline
\end{tabular}

becomes more application-oriented and affected products as well as processes (Alt 2018). Although this even comprises the information part of physical products and processes, this effect is most visible in completely information-based industries (e.g. media, finance). For example, digitalization allowed the investment banking firm Goldman Sachs to offer its investment functionalities via their mobile app Marcus and to enhance this functional scope with personal finance management features. This was undertaken in their attempt to enter the retail banking business (Jones 2021).

From a competitive perspective, the introduction, substitution and enhancement of offerings in the market has important implications. In fact, "unification of functions and the coming together of previously distinct products [...] often challenges the status quo while allowing new entrants from adjacent industries $[\ldots]$ to extend their scope and reach" (Srinivasan and Venkatraman 2020, p. 268). Convergence of technologies and products often led to disruptions of the respective industries. A well-known example is the conflict between Apple Music and Apple Records, which operated in separate industries until digitalization made them competitors and adversaries in many fierce legal proceedings (Kopp 2017). As illustrated in the early example of the multimedia industry (Wirtz 1999), convergence created new configurations and new roles in value creation. Again, the power of convergence (Hoque et al. 2011) had important implications and meanwhile seized other industries as well. In particular, the big tech companies and platform businesses have made inroads in many industries.

\section{The role of platforms}

Broadly speaking, digital platforms provide functionality to coordinate activities among multiple actors. Linking these actors from in and outside of an existing industry, collecting data from them and homogenizing this data to alleviate communication, 
brokerage and integration activities (Malone et al. 1987, p. 488) are key for digital platforms and might be enhanced with further value adding services. The latter might benefit from the application of novel or other existing technologies, such as social media, artificial intelligence, just to name a few. They contribute to a "common distribution infrastructure", which has been emphasized as being important for the production and distribution of products and services in the media industry (Rolland 2003, p. 17). The same applies to the role of the information superhighway (Wirtz 1999, p. 14), which was proposed almost thirty years ago (Benjamin and Wigand 1995). More recently, the "platformization" occurred in many industries and various types of platforms surfaced. For example, Li et al. (2015) present a data platform that collects, encapsulates and transfers data from IoT environments and offers business process integration and execution functionalities. In general, two lines of argumentation may be distinguished:

- Digital platforms as enablers of convergence. This thread is based on the reasoning that platforms have the potential to bring together developments from various domains. It might comprise several types of platforms as described in the notion of architectural convergence (Srinivasan and Venkatraman 2020). Advances in hardware platforms (e.g. powerful mobile devices with numerous functionalities) and software ecosystems (e.g. operating systems with cloud resources and app stores) combined with standards that foster interoperability (e.g. APIs for digital service usage across devices and providers) are driving innovation and convergence. Similarly, industries are converging on e-commerce platforms like Amazon, which offers services in various retail segments as well as in financial and computing services. In this sense, the coordinating and integrating role of platforms may be seen as a catalyst for convergence.

- Convergence as a driver of change for digital platforms. Remarkably, only little research may be observed on the relationship between convergence and integration. While integration may be associated with a coherently and on-purpose designed pattern with aligned elements, most research on convergence pursues a process-based understanding that not only comprises an independently evolved similarity, but also a process that produced this similarity. This interpretation from the natural sciences (see Stayton 2015) recognizes various states of similarity (or integration) that may also be measured (e.g. using the Wheatsheaf index in biology). Assuming that convergence is an ongoing temporal process of adaptation with intermediate states, competition in markets will affect networks and ecosystems alike and will lead to new business models for digital platforms (Basole 2009; Mody et al. 2020).

These thoughts highlight the proposition in an Electronic Markets editorial from 2015. It suggested the convergence of the three previously separate evolution paths "enterprise systems", "inter-organizational systems (IOS), electronic data interchange (EDI) and digital platforms" as well as the "internet" towards an inter-organizational information infrastructure. By analogy with the availability of intra-organizational information infrastructures where enterprise systems allowed for new cross-functional process designs within organizations, it was argued that the emerging inter-organizational "infrastructures may enable new networked processes, which vice versa generate demand for new technological solutions" and it was stated that "ecosystems are a prominent example of the power of convergence" (Alt and Zimmermann 2015, p. 170f). Since "convergence is not an end state" (Vukanovic 2018, p. 4), it may be assessed that the formation of such an interorganizational infrastructure is still ongoing and has become visible in many industries. An example is the banking industry where open banking and banking-as-a-platform initiatives offerings have spread in recent years (Lynn et al. 2020). Figure 1 shows this convergence in the lower part and illustrates with examples (that should not be interpreted as strictly consecutive) that additional technologies with separate evolution paths are now coming into play.

\section{The next convergence}

For sure, it is a challenging and complex undertaking to paint a picture that visualizes all relevant technological developments. Figure 1 does therefore not claim completeness, but highlights three areas where convergence has become visible and which influence what might be termed as "next convergence". Although this notion may be found in macroeconomics (Spence 2011), the following focuses on the context of digital transformation. First, for media and network convergence, so-called "triple and quadruple play" offerings appeared and promise potential in the technological dimension of the information infrastructure (e.g. Abecassis et al., 2017). Second, SMAC has been coined to denote a convergence that occurred after the inception of the multi-media World Wide Web era from 1995 until 2010 (Gopichand 2015). By combining social, mobile, analytics and cloud technologies, the SMAC concept combines many functionalities that shaped digitalization endeavors in many firms and societies worldwide. Third, one of the latest developments of convergence may be observed under the acronym DARQ, which comprises distributed ledger technology (DLT), artificial intelligence (AI), extended reality (XR), and quantum computing (QC) (Accenture 2019). It emphasizes technological developments that coevolved more or less separately from each other, but have been discussed in research and practice for decades. For example, DLT technologies combine the fields of distributed database systems and cryptology, AI the fields or rule-based (expert) systems and neurocomputing, XR the fields of IoT 
Fig. 1 Converging evolution paths with examples

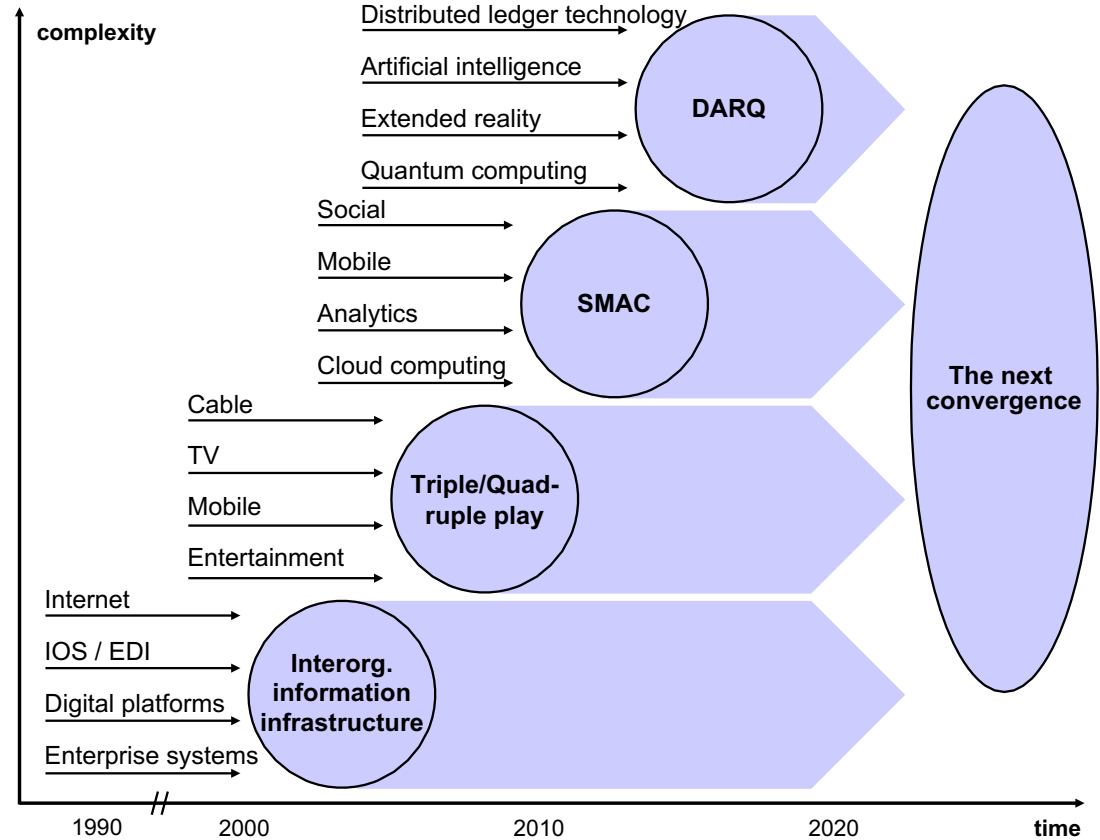

and virtual reality, and QC the fields quantum mechanics, mathematics and computer science. Although forecasting the implications of the next stage in convergence is difficult, four general developments may be expected:

- Decentralization. DLT infrastructures complement secure distributed data storage with application functionalities (e.g. smart contracts, distributed applications) that allow functionalities of centralized platforms to be decentralized (Alt 2020). Although this must not be the preferred solution for the respective application domains, the technology creates new possibilities in handling the challenging coordination tasks between participating actors in business networks. New product and process design as well as business models may arise here, especially driven by the large capitalization of many cryptocurrencies.

- Integration. Convergence will lead to more integrated devices and solutions. They will comprise larger bundles of functionality and involve more networking among previously separate devices and services. On the one hand, this will bring about more powerful services and the potential of supporting users more comprehensively. On the other hand, the development will come with the challenges of integration, where errors are quickly propagated, transparencies are not in everybody's interest and network effects accumulate market power and evoke monopolization.

- Automation. The combination of DLT with big data (BD) and AI creates a potential to digitally support transaction as well as decision support processes. Algorithms are expected to take over standardized routine processes and solve many syntactic as well as semantic problems that still impede inter-organizational and platform efficiency today. Beyond transactions, recent advances in QC have raised hopes to address complex problem solving for specific and less structured tasks in security, optimization, and also innovation. Although still being in a nascent stage, QC is recognized as disruptive for the future of platforms (Cusumano et al. 2020).

- Humanization. Fourth, the confluence of DLT, IoT, BD, AI and XR spurs hopes for a strengthening of humanaspects in digital platforms. This pertains to the empowerment of individuals in managing their daily lives and in influencing "what comes together" and what does not, in particular referring to personal data. Ultimately, convergence should serve to better support humans in their many roles, be it as a consumer, patient, citizen or employee. Like with other major technological development, the implications may also turn out as confining, coercive, fraudulent, manipulative or repressing, which calls for vigilant and careful political regulation.

\section{Articles of present issue}

For sure, "the next convergence" is only at the beginning of unfolding its transformative power. At the same time, it will not be the last convergence and Dennis' statement from 2003 is still to the point: "Those who believe convergence is dead and that any effective coming together of divergent media industries, firms or content is unlikely will, I think, be mistaken" (Dennis 2003, p. 10). The present special focuses on IoT as an element that drives the next convergence. In particular, IoT may be seen as included in the SMAC cluster since sensors are mobile devices 
themselves and are part of more complex mobile devices like smartphones. Social media use data from these mobile devices, which in turn are stored, analyzed and further processed on cloud resources. In addition, linkages to the DARQ cluster exist, for example, with blockchain and AI in the context of digital platforms (e.g. Atlam and Wills 2019; Singh et al. 2020; Wu et al. 2021). These developments are also visible in some contributions of the special issue, which is titled "Internet of things for electronic markets", the guest editors Gunasekaran Manogaran, Naveen Chilamkurti and Ching-Hsien Hsu organized a set of four papers that are introduced separately in their preface (Manogaran et al. 2021). Closely related to the IoT special issue are two papers in the general research section:

- The first shows how digital transformation not only changes a single, but multiple ecosystems. Using the examples of automotive, blockchain, financial, insurance and IIoT ecosystems, the authors Tobias Riasanow, Lea Jäntgen, Sebastian Hermes, Markus Böhm and Helmut Krcmar systematically identify the similarities and differences between a total of fifteen roles in these ecosystems. By distinguishing core, intertwined and ecosystemspecific role clusters, they contribute to the conceptual knowledge in the domain of digital platforms and ecosystems (Riasanow et al. 2021).

- The second paper focuses on smart mobility services, a field that has emerged with the convergence of networked vehicles, mobile apps and digital platforms. In their research, Thomas Schulz, Markus Böhm, Heiko Gewald and Helmut Krcmar shed light on the desires, priorities and needs of the potential customers of these services (Schulz et al. 2021). A differentiated analysis presents valuable insights on the role of factors such as price, age or functionality, which are important to understand and to design such smart services.

The remaining six general research articles represent a cluster in the domain of social media. As mentioned above, social media services and platforms are one development within the SMAC convergence. It has enhanced business processes in many organizations, in particular in customer-related processes and service industries. The contributions of the individual papers are:

- An analysis of the influence of user experiences. In a comparison of the relationships between two fashion retailers and their followers on Instagram, the authors María del Rocío Bonilla Quijada, José Luis Del Olmo Arriaga and David Andreu Domingo confirm the relevance of using social media to engage customers (del Rocío Bonilla Quijada et al. 2021). At the same time, they conclude that interactions remain at a rather low level and much potential exists for leveraging these relationships.
- Insights on how to display products across various social media platforms. The paper from Erik Ernesto Vazquez proposes that consumers could use social media to collect information about products instead of search engines and online reviews (Vazquez 2021). Based on a literature review, he suggests a conceptual framework for the knowledge acquisition process and proposes recommendations on how e-tailers should display their products on social media platforms and how relationships to (new) customers may be initiated on these platforms.

- The benefits of the information richness for consumers' buying intentions. Thomas Friedrich, Sebastian Schlauderer and Sven Overhage develop the concept of social commerce feature richness and were successful to show how this positively impacts buying intentions (Friedrich et al. 2021). From their comprehensive online experiment, they derived metrics and suggestions, which are helpful for designing social commerce implementations.

- Findings on how comments differ on various social media platforms. Another paper on social commerce analyzes travel booking websites and reveals that comments ("word of mouth") on the platforms are contingent on the community and the respective platform. The authors M. Awais Shakir Goraya, Zhu Jing, Mahmud Akhter Shareef, Muhammad Imran, Aneela Malik and M. Shakaib Akram present an analysis of the various effects and emphasize the role of trust as a mediating factor (Goraya et al. 2021).

- The role of peer groups in supporting members of a community. The authors Annette Felgenhauer, Katharina Kaufmann, Julia Klier and Mathias Klier chose the case of career counseling and show that members of a community are "in the same boat". By analyzing postings in online peer groups for career counseling in Germany, they identify several types of social support. After relating these to the peers' characteristics, the paper concludes that social media provide specific potentials that traditional one-to-one counseling are unable to offer (Felgenhauer et al. 2021).

- The peculiarities of social enterprises regarding globalization and localization. Contrary to their expectations, Mamoun Benmamoun, Hadi Alhor, Christine Ascencio and Woojong Sim found that social enterprises would favor the globalization strategy. This is in contrast to how existing e-commerce businesses standardize, which suggested to organize operations across national markets (Benmamoun et al. 2021).

\section{Community and reviewers in $\mathbf{2 0 2 0}$}

In summary, this issue was another joint effort where work from many participants "converged". We are grateful to the guest editors for organizing the review process and for 
successfully selecting four interesting papers. This also includes our appreciation to the reviewers who shared their advice as well as the authors who revised their manuscripts in multiple iterations. The same applies to the general research papers, who were overseen by associate editors. This is worth mentioning since Electronic Markets has seen another steep rise in submissions in 2020, which considerably increases the workload for editors, reviewers and the editorial office. You may obtain a feeling from the list below that shows all active reviewers in 2020 with most of them contributing repeatedly. Thank you to all of them!

In hindsight, 2020 was also a special year for Electronic Markets since the first two virtual editorial board meetings brought more participants to the (virtual) table than ever before. During the last meeting the board approved new colleagues who accepted to serve as associate editors and members of the editorial board. Our thanks go to Shahrokh Nikou from Åbo Akademi University in Finland, Anastasia Constantelou from the University of the Aegean in Greece and Hans-Ulrich Buhl from the University of Augsburg in
Germany as new associate editors and to Nizar Abdelkafi from Politecnico di Milano in Italy and Heinz-Theo Wagner from Neu-Ulm University of Applied Sciences in Germany as new editorial board members. Lina Zhou from the University of North Carolina left the board after having supported Electronic Markets for many years.

Finally, the last editorial mentioned that issue $30 / 4$ was dedicated to Rolf T. Wigand who was a long-term associate and senior editor for Electronic Markets. In the present issue, Ian MacInnes who is also an Electronic Markets board member and a former colleague of Rolf at Syracuse University, appreciates his outstanding legacy in an obituary (MacInnes 2021). Ian shares a personal view on Rolf's fascination with digital transformation, in particular of electronic markets on changing industry structures. Last but not least, it was Rolf's work on the information superhighway, which foresaw some 25 years ago that convergence would lead to disintermediation and platform businesses. This is more or less on spot of what we experience today.

\begin{tabular}{|c|c|c|}
\hline Amir Zaib Abbasi & Ulla Hakala & Loo Geok Pee \\
\hline Babak Abedin & Kazem Haki & Krassie D Petrova \\
\hline Amjad Abu ELSamen & Shengnan Han & Matti Pihlajamaa \\
\hline Lailatul Faizah Abu Hassan & Robert R Harmon & Jens Poeppelbuss \\
\hline Abubakar Mohammed Abubakar & Marikka Heikkilä & Oliver Posegga \\
\hline Martin Adam & Andreas Hein & Günter Prockl \\
\hline Rupesh K. Agrawal & Andreas Henrich & Andreja Pucihar \\
\hline Petri Ahokangas & Oliver Hinz & Dorina Rajanen \\
\hline Shahriar Akter & Hartmut Hoehle & Isabel Ramos \\
\hline Mazen Ali & Wout Hofman & Bharat Rao \\
\hline Saqib Ali & Christopher Patrick Holland & Ulrich Reimer \\
\hline Rainer Alt & Val Anne Hooper & Olaf Reinhold \\
\hline Jörn Altmann & Jianwei Hou & Uwe Riss \\
\hline Norm Archer & Tianhang Huang & Maximilian Röglinger \\
\hline Pierre-Emmanuel Arduin & Inkyoung Hur & Kristina Rosenthal \\
\hline Alexia Athanasopoulou & Ulla Hytti & Angela Roth \\
\hline Mahdi Atia & Maria-Eugenia Iacob & Boriana Rukanova \\
\hline Norman Au & Efosa Carroll Idemudia & Mijalche Santa \\
\hline Volker Bach & Claire Ingram Bogusz & Gerhard Satzger \\
\hline José Ángel Bañares & Stanislav Ivanov & Detlef Schoder \\
\hline Snehasish Banerjee & Dietmar Jannach & Maximilian Schreieck \\
\hline Christine Bauer & Marijn Janssen & Gerhard Schwabe \\
\hline Ingrid Bauer & Reinhard Jung & Jürgen Seitz \\
\hline Larissa Becker & Özgür Kafali & Zhen Shao \\
\hline Steven Bellman & Lele Kang & Seunghun Shin \\
\hline Katerina Berezina & Myung Ja Kim & Muhammad Nadeem Shuakat \\
\hline Benedikt Berger & Ranjan B Kini & Åsa Smedberg \\
\hline Markus Bick & Mathias Klier & Matthias Söllner \\
\hline Baidyanath Biswas & Sören Köcher & Pedro Soto-Acosta \\
\hline Francisco Javier Blanco-Encomienda & Chulmo Koo & Konstantina Spanaki \\
\hline
\end{tabular}


(continued)

\begin{tabular}{|c|c|c|}
\hline$\overline{\text { Markus Böhm }}$ & Antonia Köster & Martin Spann \\
\hline Roger Bons & Helmut Krcmar & Newton Spolaôr \\
\hline Harry Bouwman & Kevin Kuan & Katarina Stanoevska-Slobeva \\
\hline Jan vom Brocke & Pradip Kumar Sharma & Dennis Marten Steininger \\
\hline Ricardo Buettner & Tyge-F. Kummer & Lucas Stich \\
\hline Dimitrios Buhalis & Karl R. Lang & Emanuel Stoeckli \\
\hline Hans Ulrich Buhl & Ulrike E. Lechner & Stefan Strecker \\
\hline Jacques Bulchand & Ho Geun Lee & Frantisek Sudzina \\
\hline Peter Buxmann & Minwoo Lee & Ali Sunyaev \\
\hline Christer Carlsson & Christine Legner & Reima Suomi \\
\hline Sohail Chaudhry & Christiane Lehrer & Eric-Oluf Svee \\
\hline Langtao Chen & Jan Marco Leimeister & Samar I. Swaid \\
\hline Christy Cheung & Uwe Leimstoll & Luis Téran \\
\hline CB Choi & Hongxiu Li & Rahul Thakurta \\
\hline Sujeong Choi & Tao Li & Frédéric Georges Thiesse \\
\hline Youngjoon Choi & Yi Li & Paul H. Timmers \\
\hline Raffaele Ciriello & Qinyu Liao & Artemi Tonikidou \\
\hline Michel Clement & Dália Liberato & Luba Torlina \\
\hline Anastasia Constantelou & Weng Marc Lim & Manuel Trenz \\
\hline Omar Andrés Carmona Cortés & Juho Lindman & Aarni Tuomi \\
\hline John D'Ambra & Yong Liu & Frank Ulbrich \\
\hline Mark De Reuver & Zhiyong Liu & Nils Urbach \\
\hline Henk J. de Vries & Fabio Lobato & Rogier van de Wetering \\
\hline Giacomo Del Chiappa & June Lu & Elmira Van den Broek \\
\hline Yi Ding & Long Ma & Jørgen Veisdal \\
\hline Xuebing Dong & Xiao Ma & Buvaneshwaran Venugopal \\
\hline Sara D'Onofrio & Wolfgang Maass & Heinz-Theo Wagner \\
\hline Paul Drews & Maria Madlberger & Samuel Fosso Wamba \\
\hline Paulo Duarte & Christian Maier & Lisa Wan \\
\hline Nestor Duch-Brown & Carla Bonato Marcolin & Yun Wan \\
\hline Katharina Ebner & Marjeta Marolt & Ping Wang \\
\hline Roman Egger & Malte Martensen & Sascha Weigel \\
\hline Jan Fabian Ehmke & Christian Matt & Christof Weinhardt \\
\hline Christian Engel & Pascal Mehrwald & Lauri Wessel \\
\hline Ramazan Esmeli & Luiz Mendes-Filho & Manuel Wiesche \\
\hline Torsten Eymann & Matthias Meyer & Maria A. Wimmer \\
\hline Michael Fellmann & Karl Jacob Mickelsson & Axel Winkelmann \\
\hline Jerry Fjermestad & Qingfei Min & Jochen Wirtz \\
\hline Lawrence Fong & Milad Mirbabaie & James Richard Wolf \\
\hline Maximilian Förster & Matthias Murawski & Ziang Xiao \\
\hline Zhimin Gao & Jamie Murphy & Sung-Byung Yang \\
\hline Judith Gebauer & Julia Neidhardt & Benjamin Yen \\
\hline Nitza Geri & Barbara Neuhofer & Ahad Zareravasan \\
\hline Richard Glavee-Geo & Shahrokh Nikou & Ji Zhang \\
\hline Ulrich Gnewuch & Chinedu Ossai & Yin Zhang \\
\hline Jaap Gordijn & Boris Otto & Naim Zierau \\
\hline Ulrike Gretzel & Kwangsoo Park & Hans-Dieter Zimmermann \\
\hline Nick Hajli & Sangwon Park & Steffen Zimmermann \\
\hline
\end{tabular}


Funding Open Access funding enabled and organized by Projekt DEAL.

Open Access This article is licensed under a Creative Commons Attribution 4.0 International License, which permits use, sharing, adaptation, distribution and reproduction in any medium or format, as long as you give appropriate credit to the original author(s) and the source, provide a link to the Creative Commons licence, and indicate if changes were made. The images or other third party material in this article are included in the article's Creative Commons licence, unless indicated otherwise in a credit line to the material. If material is not included in the article's Creative Commons licence and your intended use is not permitted by statutory regulation or exceeds the permitted use, you will need to obtain permission directly from the copyright holder. To view a copy of this licence, visit http://creativecommons.org/licenses/by/4.0/.

\section{References}

Abecassis, D., Guitard, Y., \& Kende, M. (2017). Convergence of TV and digital platforms: Increased innovation and competition for advertisers' budgets. Analysys Mason, https://ssrn.com/abstract= 3092181.

Accenture (2019). The post-digital era is upon us: Are you ready for what's next. Accenture Technology Vision 2019. https://www. accenture.com/_acnmedia/PDF-94/Accenture-TechVision-2019. Tech-Trends-Report.pdf, accessed Feb. 22, 2021.

Alt, R. (2018). Electronic Markets on digitalization. Electronic Markets, 28(4), 397-402. https://doi.org/10.1007/s12525-018-0320-7.

Alt, R. (2020). Electronic Markets on blockchain markets. Electronic Markets, 30(2), 181-188. https://doi.org/10.1007/s12525-02000428-1.

Alt, R., \& Zimmermann, H.-D. (2015). Editorial 25/3: Electronic Markets on ecosystems and tourism. Electronic Markets, 25(3), 169-174. https://doi.org/10.1007/s12525-015-0197-7.

Atlam, H. F., \& Wills, G. (2019). Intersections between IoT and distributed ledger. Advances in Computers, 115, 73-113. https://doi.org/ 10.1016/bs.adcom.2018.12.001.

Balbi, G. (2017). Deconstructing "media convergence": A cultural history of the buzzword, 1980s-2010s. In S. Sparviero, C. Peil, \& G. Balbi (Eds.), Media convergence and deconvergence (pp. 31-51). Cham: Palgrave. https://doi.org/10.1007/978-3-319-51289-1_2.

Basole, R. C. (2009). Visualization of interfirm relations in a converging mobile ecosystem. Journal of Information Technology, 24(2), 144159. https://doi.org/10.1057/jit.2008.34.

Benjamin, R., \& Wigand, R. (1995). Electronic markets and virtual value chains on the information superhighway. Sloan Management Review, 36(2), 62-72.

Benmamoun, M., Alhor, H., Ascencio, C., \& Sim, W. (2021). Social enterprises in electronic markets: Web localization or standardization. Electronic Markets, 31(1). https://doi.org/10.1007/s12525020-00430-7.

Castells, M. (2007). Communication, power and counter-power in the network society. International Journal of Communication, 1, 238266.

Crowley, D. N., Curry, E., \& Breslin, J. G. (2014). Leveraging social media and IoT to bootstrap smart environments. In N. Bessis \& C. Dobre (Eds.), Big data and internet of things: A roadmap for smart environments. Cham: Springer. https://doi.org/10.1007/978-3-31905029-4 16.

Cusumano, M. A., Yoffie, D. B., \& Gawer, A. (2020). The future of platforms. MIT Sloan Management Review, 61(3), 46-54.

del Rocío Bonilla Quijada, M., Arriaga, J. L. D. O., \& Domingo, D. A. (2021). Insights into user engagement on social media. Findings from two fashion retailers. Electronic Markets, 31(1). https://doi. org/10.1007/s12525-020-00429-0.

Dennis, E. E. (2003). Prospects for a big idea - is there a future for convergence? International Journal on Media Management, 5(1), 7-11. https://doi.org/10.1080/14241270309390013.

Felgenhauer, A., Kaufmann, K., Klier, J., \& Klier, M. (2021). In the same boat: Social support in online peer groups for career counseling. Electronic Markets, 31(1). https://doi.org/10.1007/s12525-01900360-z.

Friedrich, T., Schlauderer, S., \& Overhage, S. (2021). Some things are just better rich: How social commerce feature richness affects consumers' buying intention via social factors. Electronic Markets, 31(1). https://doi.org/10.1007/s12525-019-00374-7.

Gopichand, M. (2015). Cloud computing: An introduction to SMAC. International Journal of Innovative Science, Engineering \& Technology, 3(7), 666-671.

Goraya, M. A. S., Jing, Z., Shareef, M. A., Imran, M., Malik, A., \& Akram, M. S. (2021). An investigation of the drivers of social commerce and e-word-of-mouth intentions: Elucidating the role of social commerce in E-business. Electronic Markets, 31(1). https://doi.org/ 10.1007/s12525-019-00347-w.

Greenstein, S. G., \& Khanna, T. (1997). What does industry convergence mean? In D. B. Yoffie (Ed.), Competing in the age of digital convergence (pp. 201-226). Boston: Harvard Business Press.

Gustavsson, V., \& Schwarz, E. J. (2013). Business modelling and convergence. In S. Diehl \& M. Karmasin (Eds.), Media and convergence management (pp. 9-23). Berlin: Springer. https://doi.org/10. 1007/978-3-642-36163-0 2.

Hens, F. J., \& Caballero, J. M. (2008). Triple play: Building the converged network for IP, VoIP and IPTV. Chichester: Wiley.

Hoque, F., Walsh, L., Mirakaj, D., \& Bruckner, J. (2011). The power of convergence: Linking business strategies and technology decisions to create sustainable success. Amacom: New York etc.

Hübner, A., Holzapfel, A., \& Kuhn, H. (2016). Distribution systems in omni-channel retailing. Business Research, 9(2), 255-296. https:// doi.org/10.1007/s40685-016-0034-7.

Jones, C. (2021). Goldman Sachs' Marcus online banking app has personal touch to run investments. The Times, February 17, https:// www.thetimes.co.uk/article/goldman-sachs-marcus-onlinebanking-app-has-personal-touch-to-run-investments. Accessed 21 Feb 2021

Kopp. S. W. (2017). Apples to apples: Corporate diversification and trademark troubles. In: Kennedy, A.-M. (Ed.). Explorations in globalization and glocalization: marketing history through the ages. Proceedings $18^{\text {th }}$ Conference on Historical Analysis and Research in Marketing (CHARM), Charm Association, Liverpool, pp. 281282.

Li, Q., Luo, H., Xie, P.-X., Feng, X.-Q., \& Du, R.-Y. (2015). Product whole life-cycle and omni-channels data convergence oriented enterprise networks integration in a sensing environment. Computers in Industry, 70, 23-45. https://doi.org/10.1016/j.compind.2015.01. 011.

Lynn, T., Rosati, P., \& Cummins, M. (2020). Exploring open banking and banking-as-a-platform: Opportunities and risks for emerging markets. In D. Klonowski (Ed.), Entrepreneurial finance in emerging markets (pp. 319-334). Cham: Palgrave Macmillan. https://doi. org/10.1007/978-3-030-46220-8_20.

MacInnes, I. (2021). The stellar life and career of Rolf Wigand. Electronic Markets, 31(1). https://doi.org/10.1007/s12525-021-00462-7.

Maiorescu, I., Bucur, M., Georgescu, B., Moise, D., Strat, V. A., \& Zgură, L. D. (2020). Social media and IOT wearables in developing marketing strategies. Do SMEs differ from large enterprises? Sustainability, 12(18), 7292. https://doi.org/10.3390/su12187292.

Malone, T. W., Yates, J., \& Benjamin, R. I. (1987). Electronic markets and electronic hierarchies. Communications of the ACM, 30(6), 484-497. https://doi.org/10.1145/214762.214766. 
Manogaran, G., Chilamkurti, N., \& Hsu, C.-H. (2021). Internet of things for electronic markets. Electronic Markets, 31(1).

Meikle, G., \& Young, S. (2011). Media convergence: Networked digital media in everyday life. Houndmills Basingstoke: Palgrave Macmillan.

Mody, M., Wirtz, J., So, K. K. F., Chun, H. H., \& Liu, S. Q. (2020). Twodirectional convergence of platform and pipeline business models. Journal of Service Management, 31(4), 693-721. https://doi.org/10. 1108/JOSM-11-2019-0351.

Park, S. E. (2019). Technological convergence: Regulatory, digital privacy, and data security issues. Washington: Report R45746, Congressional Research Service.

Riasanow, T., Jäntgen, L., Hermes, S., Böhm, M., \& Krcmar, H. (2021). Core, intertwined, and ecosystem-specific clusters in platform ecosystems: Analyzing similarities in the digital transformation of the automotive, blockchain, financial, insurance and IIoT industry. Electronic Markets, 31(1). https://doi.org/10.1007/s12525-02000407-6.

Rolland, A. (2003). Convergence as strategy for value creation. Journal on Media Management, 5(1), 14-24. https://doi.org/10.1080/ 14241270309390015.

Schulz, T., Böhm, M., Gewald, H., \& Krcmar, H. (2021). Smart mobility - An analysis of potential customers' preference structures. Electronic Markets, 31(1). https://doi.org/10.1007/s12525-02000446-z.

Shan, Y., Quao, Y., Li, B., \& Wang, J. (2020). A process convergence approach for crossover services based on message flow partition and merging. Proceedings International Conference on Services Computing (SCC), IEEE, (pp. 178-186). https://doi.org/10.1109/ SCC49832.2020.00031.

Singh, S. K., Rathore, S., \& Park, J. H. (2020). BlockIoTIntelligence: A blockchain-enabled intelligent IoT architecture with artificial intelligence. Future Generation Computer Systems, 110, 721-743. https://doi.org/10.1016/j.future.2019.09.002.
Spence, A. M. (2011). The next convergence: The future of economic growth in a multispeed world. New York: Farrar, Straus and Giroux.

Srinivasan, A., \& Venkatraman, V. N. (2020). Architectural convergence and platform evolution: Empirical test of complementor moves in videogames. IEEE Transactions on Engineering Management, 67(2), 266-282. https://doi.org/10.1109/TEM.2018.2881560.

Stayton, C. T. (2015). The definition, recognition, and interpretation of convergent evolution, and two new measures for quantifying and assessing the significance of convergence. Evolution, 69(8), 2140 2153. https://doi.org/10.1111/evo.12729.

Stobbe, A., \& Just, T. (2006). The dawn of technological convergence. Economics report no. 56, Deutsche Bank Research, Frankfurt/Main

Vazquez, E.E. (2021). Effect of an e-retailer's product category and social media platform selection on perceived quality of e-retail products. Electronic Markets, 31(1). https://doi.org/10.1007/s12525-02000394-8.

Vukanovic, Z. (2018). The influence of digital convergence/divergence on digital media business models. In: Clua, E., Roque, L., Lugmayr, A., \& Tuomi, P. (Eds), Entertainment computing, Proceedings ICEC 2018. Lecture Notes in Computer Science, vol 11112. Cham: Springer. https://doi.org/10.1007/978-3-319-99426-0_13.

Wirtz, B. W. (1999). Convergence processes, value constellations and integration strategies in the multimedia business. International Journal on Media Management, 1(1), 14-22. https://doi.org/10. 1080/14241279909384482.

Wu, Y., Dai, H.-N., \& Wang, H. (2021). Convergence of blockchain and edge computing for secure and scalable IIoT critical infrastructures in industry 4.0. IEEE Internet of Things Journal, 8(4), 2300-2317. https://doi.org/10.1109/JIOT.2020.3025916.

Publisher's note Springer Nature remains neutral with regard to jurisdictional claims in published maps and institutional affiliations. 